Original Research Paper

\title{
Mechanical Properties of Waste Biaxially Oriented Polypropylene Metallized Films (BOPP), LLDPE: LDPE Films with Sisal Fibres
}

\author{
Kiran Rohit and Savita Dixit \\ Maulana Azad National Institute of Technology Bhopal, India
}

\author{
Article history \\ Received: 29-07-2016 \\ Revised: $13-10-2016$ \\ Accepted: 22-10-2016 \\ Corresponding Author \\ Savita Dixit \\ Maulana Azad National \\ Institute of Technology Bhopal, \\ India \\ Tel : +91-755- 4051653 \\ Fax: + 91-755-2670562 \\ Email: savitadixit1@yahoo.com
}

\begin{abstract}
The current work describe the enhancement and improvisation of polymer composite repose of sisal fiber reinforcement, Biaxially Oriented Polypropylene (BOPP) and thermoplastic LLDPE: LDPE particulate fillers. The composite were prepared with fiber content 5, 10, 15 and 20\% (by weight). The composite are characterized with respect to their mechanical properties (Tensile, flexural and impact strength) were studied. Tensile strength showed an increasing trend with increase in fiber content up to $15 \%$ then decreases. Impact strength increases with the increase in fiber content. SEM, DSC analysis shows the morphology and material identification respectively.
\end{abstract}

\section{Keyword: Polymer Blends, Sisal Fiber, WMBPs, LLDPE, LDPE BOPP}

\section{Introduction}

Nowadays, In light of the governmental emphasis due to the social, economic and ecological awareness on the environmental regulations and sustainability, the proper utilization of natural resources and wastes are strongly encouraged. The properties of natural fibers polymers composites vary with fiber type, source as well as fiber structure. The natural fiber reinforced polymer composite, became newly highly valuable materials. In particular the natural fiber will not only decrease waste disposal problems, but also it will reduce environmental pollution.

Subsequently, the Natural Fiber Composites (NFCs) became alternative for numerous industrial application. In NFCs, natural fibres are used as fillers or reinforcing materials for polymer matrices (Sapuan et al., 2013; AL Oqla and Sapuan, 2014; AL Oqla et al., 2014a; Thakur et al., 2012; Thakur and Thakur, 2014). The proper utilization of natural fibres not only resolves the waste disposal problem but also reduces environmental pollution (AL Oqla and Sapuan, 2014; AL Oqla et al., 2014a; Kalia et al., 2011a; AL Oqla et al., 2015a).

Natural fiber composite have been proven and emerged as an attractive materials from environmental point of view. However, during the recent decades, natural fibers have been used as an alternative reinforcement in polymer composites. Composite pay attention over many researchers and scientists due to their advantages over conventional glass and carbon fibers (AL Oqla et al., 2014b; 2015b; Alves et al., 2010).
The first steps towards ecofriendly centered on substitution predominant fibres, like fiber (GF), by natural fibres, whereas maintaining the polyolefin matrix in this sense Plastic Polypropylene (PP), High Density Polythene (HDPE) and Poly Vinyl Chloride (PVC) are one amongst the foremost used matrices.

Megiatto et al. (2010) investigate the toughening of phenolic resin thermosetting and its composites strengthened with sisal fibers, victimization HydroxylTerminated Polybutadiene Rubber (HTPB) as each impact modifier and coupling agent. Substantial increase within the impact strength of the thermosetting was achieved by the addition $10 \%$ of HTPB. Scanning microscopy (SEM) pictures of the fabric with $15 \%$ HTPB content discovered the formation of some rubber aggregates that reduced the potency of the toughening mechanism.

The natural fibers containing composites are more ecofriendly and are use in are used in transportation (automobiles, railway coaches), building, packaging and insulation materials (AL Oqla et al., 2014b; Alves et al., 2010; Thakur et al., 2014; AL Oqla et al., 2015c). The main benefits of the natural fibres before of glass fiber are its lower density that enable high specific mechanical properties, its relatively low value and high accessibility and its lower instrumentality abrasion throughout preparation and producing.

The effects of varied chemical treatments on the mechanical and thermal properties of natural fibres reinforcements thermoset and thermoplastics composites were studied. Because of its deliquescent nature natural 
fibers possess variety of drawbacks like higher water absorption, inferior hearth resistance and lower mechanical properties restricted its applications (Sapuan et al., 2013; AL Oqla and Sapuan, 2014; AL Oqla et al., 2014; Mohammed et al., 2015).

In augementation, these NFCs show several advantages and superior characteristics over traditional composites due to the low cost and densities alone with acceptable specific strengths and moduli (AL Oqla et al., 2014b; Kalia et al., 2011b; AL Oqla et al., 2010) which offer the opportunity to produce light weight products. Furthermore, NFCs are also used in producing recyclable bio-degradable products (Faruk et al., 2012; Kalia et al., 2011b; AL Oqla et al., 2015c).

Highest mechanical properties showed by these materials allowed it consideration as an alternative to glass fiber reinforced composites for semi structural engineering applications (Scarponi and Messano, 2015; Scarponi and Andreotti, 2009; Koronis et al., 2013). They additionally induce less pollution due to their natural character and combustibility while not the assembly of toxic gases or residues. Many studies have shown that natural fibres have had a awfully slight impact on the surroundings in comparison to glass fibres.

Caputo et al. (2015) studied the broken plates of carbon-epoxy on onset and low rate impact injury, a numerical investigation has been semiconductor diode and finite part model has been created by victimization the finite part code abaqus. The world approach utilized; in the native a part of the model the stuff has been sculpturesque layer by layer. The planned numerical procedure, based on specific finite part methodology, in the kind enforced, in the kind enforced within the algorithms abaqus code, seems acceptable for the coincidental study of the inter-laminar and intra-laminar injury in composite structure.

Riccio et al. (2016) the mechanical response of fiberreinforced composite laminates beneath impact masses. Will be terribly tough attributable to the prevalence of coinciding failure phenomena. Indeed, as a consequence of low speed impacts, intra-laminar damages, like fibre and matrix cracking and inter-laminar damages, like delaminations, will happen at the same time.

Antonucci et al. (2016) they reported that the different NDE techniques on specimens made by a new process labeled as pulse infusion very crucial for voids content under critical loading conditions.

The incorporation of natural fibres in thermoplastics is a stimulating subject owing to many alternative factors. Natural fibres combine good mechanical properties with a low specific mass. Moreover, their biodegradability will contribute to a healthy scheme and their low production prices build them terribly attentiongrabbing for industries.

In the present scenario, the wastes generated by plastics pose as an unmanageable environmental problem. Many ongoing researches are directed towards providing a solution to cater to this problem. In this context, Green Technology provides a unique method to provide answers towards sustainable development. Reuse of waste plastic materials is one of the best methods of using latest technology to solve the long impending threats that can affect our lives even at the grass root level. The current work is a step towards collaborating common technologies with issues related with sustainable development.

The production of plastic products is carried out using various moulding machine such as injection, extrustion, blow moulding compression etc. utilising virgin plastic material film polymer industries but the challenge lies in managing the waste produced at the factory level and post consumer waste which lies unattended. Two types of waste that are generated are characterised as recycleable and non recycleable waste.

Recyclable waste includes materials which are produced as rejections, lumps and trims that can be recycled at the factory level with primary extrusion techniques. These type of wastes are also generated as the post consumer waste which are collected by Rag pickers and Recycled by various recyclers having segregation, cutting, washing, drying, high speed mixing and finally extrusion to produce recycled granules.

The other category of the waste generated is the non recyclable waste which cannot be recycled due to presence of the metallic substrate which resists the flow of the melt and can choke the die thus hampering the extrusion recycling process. This category of Plastics waste cannot be recycled and thus poses a threat to the environment.

The scope of this study is to effectively use the waste BOPP as filler with polymer matrix LLDPE: LDPE and reinforced with natural fibres (sisal) to produce useful products which may replace wooden boards soft boards and ply boards, covers etc. The main advantages of the boards produced by the use of non- recyclable metallised films are the strength to weight ratio, which makes it strong and light weight.

\section{Material and Methods}

\section{LDPE: LLDPE}

The combination of LDPE: LLDPE films was collected from Scrap Dealers of Bhopal in the New Kabarkhana Area of Bhopal. This scrap generally belongs to the family of Packaging film of Milk Pouches. The Packaging film used for milk pouches is Co-extruded from a two layer Extrusion Blown film unit Kabra extrusion Techniques, Mumbai. The material is sourced from M/s Reliance Industries Ltd., Jamnagar Gujarat, has LLDPE grade F19010, density $0.918 \mathrm{gm} / \mathrm{cc}$, MFI $0.9 \mathrm{gm} / 10 \mathrm{~min}$ and LDPE grade $0.922 \mathrm{gm} / \mathrm{cc}$ of MFI $4 \mathrm{gm} / 10 \mathrm{~min}$. The LDPE: LLDPE films was cut into smaller sizes up to $5-7 \mathrm{~mm}$ and then put into agglomerator, into smaller particle(powder) which are further converted into smaller lumps. 
Table 1. Shows the chemical composition of sisal fibres (Kalia et al., 2011b)

\begin{tabular}{ll}
\hline Constituents & Percentages (\%) \\
\hline Cellulose & $66-72$ \\
Hemicellulose & 12 \\
Lignin & $10-14$ \\
Pectin & 0.9 \\
Moisture & $6-10$ \\
Ash & $1-2$ \\
\hline
\end{tabular}

\section{Sisal Fiber}

In this analysis, sisal fibres were obtained from native sources and were used as reinforcement within the composite. Table 1 shows the chemical composition of sisal fibres. The fibres were cleansed manually, straightened with a comb device and completely washed with water, then dried in open sun light for $48 \mathrm{~h}$ then place in an exceedingly hot air oven for $2 \mathrm{~h}$ to remove the additional dirt and wet. Once this fibres were shredded into 25-30 millimeter long with a manual chopper.

\section{BOPP Metallized Films}

The scrap was obtained from scrap dealers of Bhopal who have collected the waste/rejected BOPP film from various industries in and around Bhopal, but were unable to reprocess the same. This film waste was ground to smaller size with a plastics scrap grinder sourced from $\mathrm{M} / \mathrm{s}$ Suresh Engineering works Indore with a capacity of $70 \mathrm{~kg} \mathrm{~h}^{-1}$. This waste was shredded up to the Length 15$20 \mathrm{~mm}$ and ground film width of 5-7 $\mathrm{mm}$ with a grinder speed of $30-40 \mathrm{~kg} \mathrm{~h}^{-1}$. Upon testing in the Laboratory at CIPET Bhopal. The above BOPP metallized film waste was found to be of grade HO34SG, MFI $3.4 \mathrm{gm} / 10 \mathrm{~min}$ which was sourced from authorized dealer of Reliance Industries Limited, Gujarat.

\section{Experimental Setup}

\section{Composite Preparation}

The composite of LDPE: LLDPE film and metallized BOPP film is prepared along with reinforcement of Sisal fibre and a study was conducted by varying the content of sisal fibres in the polymer matrix.

Known weight percentage of sisal fiber was spread between two halves of the compression mold randomly and a load of 20 tons was applied by hydraulic compression press (M/s Hind Hydraulics-40 Tonnes capacity, Mumbai) to form a $1.5 \mathrm{~mm}$ sheet of sisal fibres. The grind material of LDPE: LLDPE and metallized BOPP film was crushed in a water jacketed agglomerator of $\mathrm{M} / \mathrm{s}$. Suresh Engineering Works, Indore, for half an hour. Water was poured in the agglomerator pop-up-hole and the crushed LDPE: LLDPE powder (having a low temperature softening point) was converted to lumps while the metallized BOPP film was chopped into smaller size strands. This crushed material was then evenly spread on the bottom part of the Two Plate mold. The size of the mold is $160 \times 160 \times 4 \mathrm{~mm}$. The compressed sheet of sisal fiber was placed in the middle portion of the mix and further again the crushed material from the agglomerator was spread evenly on the top layer of the mold cavity. Thus the Sisal fiber sheet prepared was sandwiched between the LDPE: LLDPE and BOPP agglomerate. The hot press was pre-set at $130^{\circ} \mathrm{C}$ for the upper half of the Bolster and $130^{\circ} \mathrm{C}$ for the bottom bolster of the press. The mold was placed between the lower and the upper Bolsters of the hot press and clamped at a tonnage of 40 tonnes for $30 \mathrm{~min}$. After 30 min the mould was then removed from the hot press and cooled to room temperature. The mould was later opened to remove the composite sheet. Finally a $4 \mathrm{~mm}$ thick composite sheet was formed.

\section{Tensile Testing}

Tensile strength of composite samples determined by following ASTM D 638 using an Instron model 3382 testing machine. Dumbbell formed samples of composites with dimension $150 \times 12.99 \times 4 \mathrm{~mm}$ were tested. Samples were tested to failure beneath tension at a crosshead displacement of 50 millimeter. An extensometer was connected to the guage section of the sample for strain measuring. Five samples were test to checked the dependableness of results.

\section{Impact Test}

Tinius Olsen impact 104 machine is used to conduct Izod impact of rectangular samples with dimensions $67 \times 10 \times 3.5 \mathrm{~mm}$ were tested using an Izod impact tester. For each composition five specimens were tested and average data were reported.

\section{Results and Discussion}

\section{Tensile Properties}

Figure 1 presents the stress-strain behaviour of LLDPE: LDPE and BOPP with sisal fiber composite. It will be determined that stress will increase linearly with the rise in strain. However, once it reaches bound stress values, non linear behaviour is noticed for the $20 \%$ fiber loading wherever strain will increase at low stress before undergoing failure. Table 2-7 show the mechanical properties of WMBPs and general information of polymer and its properties. By increasing fiber content from 0 to $20 \%$, it can be observed that failure takes place as much as lower strain rate. Furthermore, when fiber content was increased up to $20 \%$ failure took place at the lowest strain rate. The high strain rate for low fibre content is attribute to the nature of LDPE: LLDPE and BOPP blends.

Figure 1 shows the effect of the fiber content on the tensile strength of LDPE: LLDPE and BOPP with sisal fibre as composites. It is detected that the strength is decreasing with increases in fibre content. The tensile 
strength is $13.8 \mathrm{M} \mathrm{Pa}, 17.5 \mathrm{M} \mathrm{Pa}, 18.7 \mathrm{M} \mathrm{Pa}, 25.8 \mathrm{M} \mathrm{Pa}$, $22.7 \mathrm{M} \mathrm{Pa}$ for $0,5,10,15$ and $20 \%$ fiber content; respectively. Fibres work as carrier of load within the matrix. Sensible durability depends additional on effective and uniform stress distribution. By the rule of the mixture, adding fibres with a awfully high strength to the matrix with low tensile strength ought to lead to increasing durability of the composite, if surface bonding is good. Since, there is drop in the tensile strength as observed in the Fig. $4 \mathrm{~d}$ it is thought that interfacial bonding is poor, this is also supported with the morphological observation reports in SEM which shows poor adhesion between fiber and matrix. Figure
4 shows SEM of the fracture surface of tensile specimens. In general, it can be observed that there are fibre pullouts and gaps between fibres and matrix. This indicates to the poor fiber matrix adhesion. Figure 4a-d shows SEM for the fracture surface of a tensile specimen for $5,10,15$ and $20 \%$ fiber content composites. It can be noticed in all figures that there is strong fiber/matrix adhesion as the percentage of fiber content increases tensile was increasing. By comparing these Fig. 4a-d it is observed that population of fibres is increasing. Thus, more strain failure points are contributing to increase the tensile strength in higher fiber content.

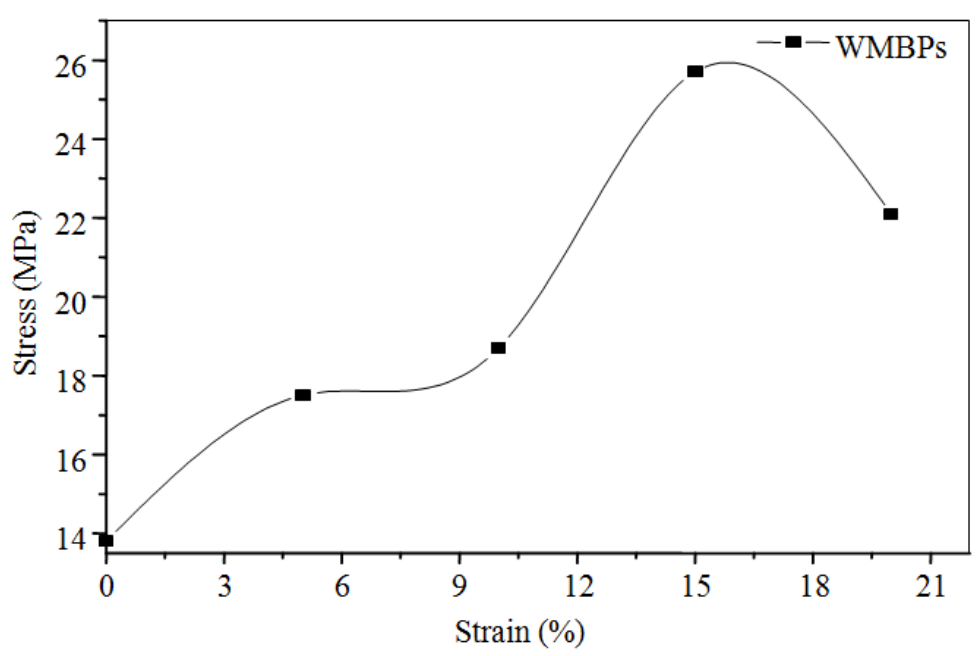

Fig. 1. Stress-strain behavior of different fiber content of WMBPs

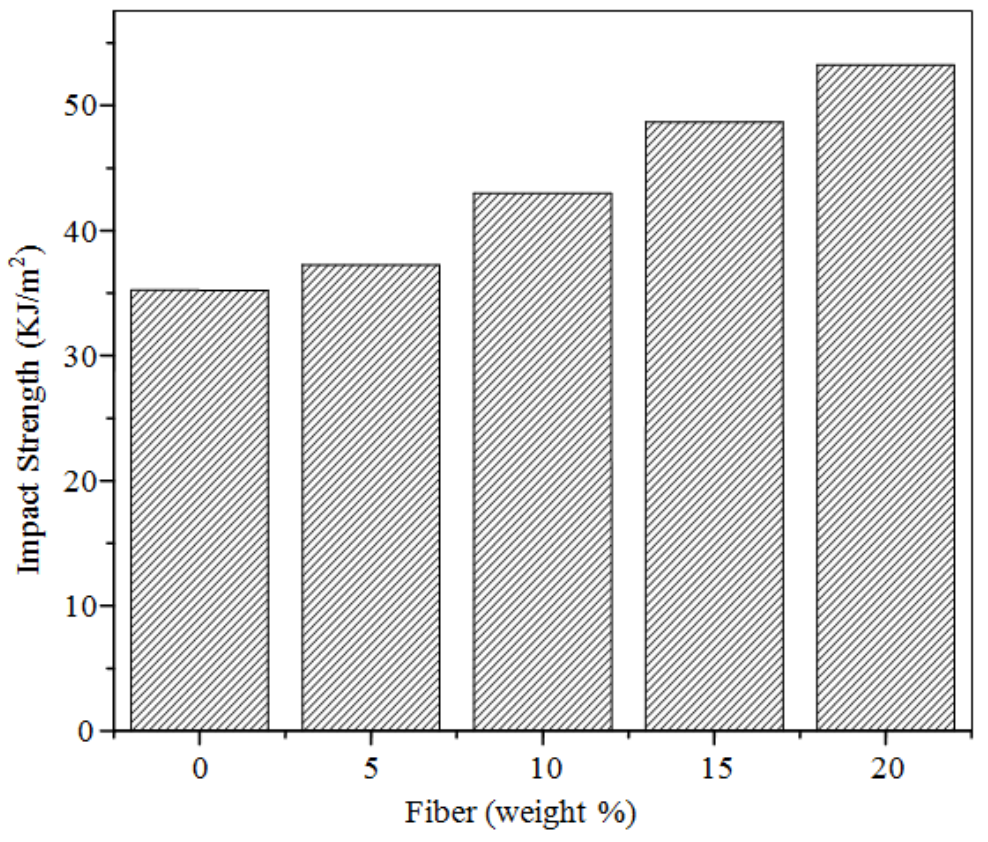

Fig. 2. Effect of fiber content on impact strength of different content of WMBPs 


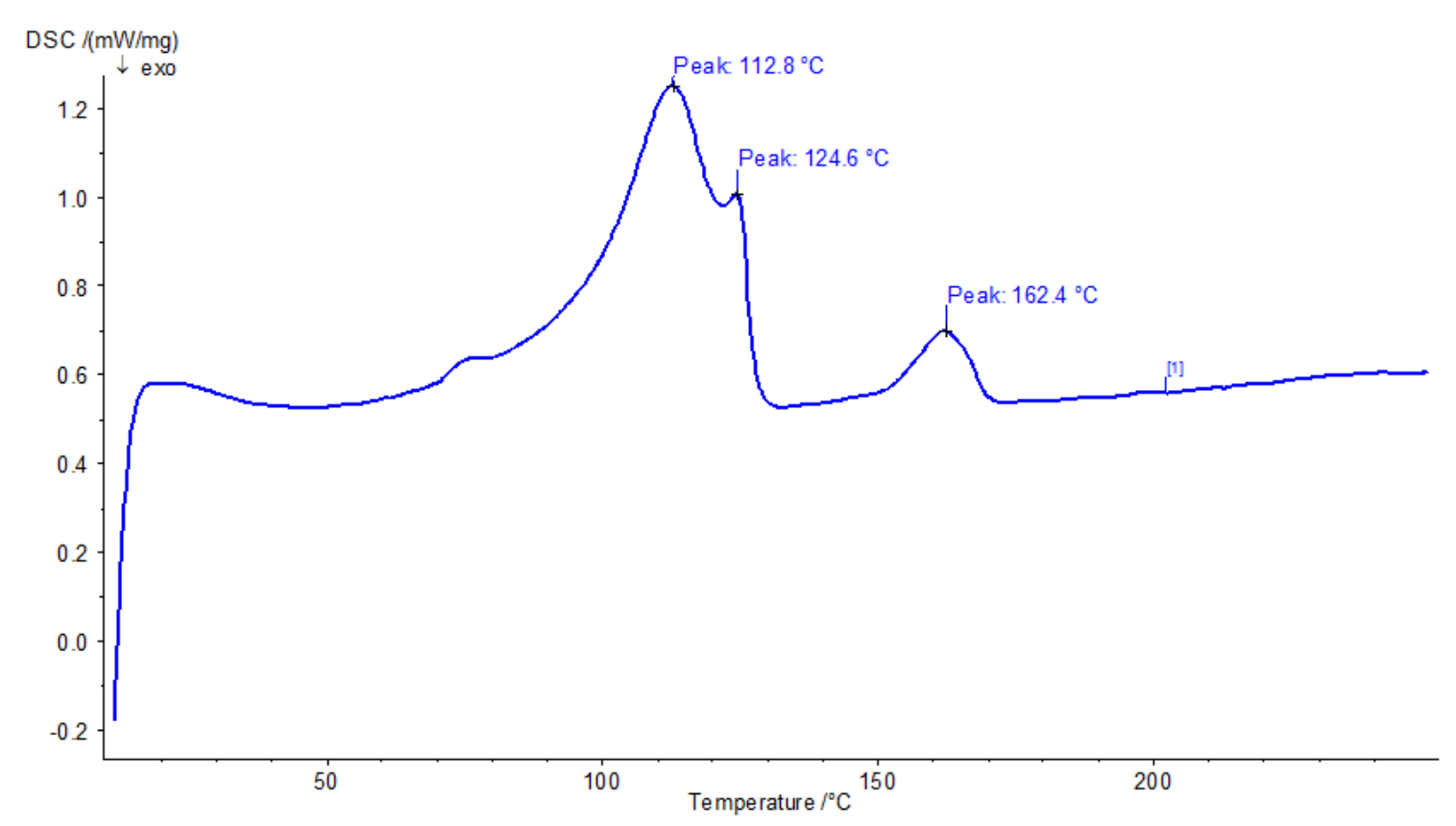

Fig. 3. Differential Scanning Colorimetry (DSC) graph of LLDPE, LDPE and BOPP shows the softening point of the polymeric material

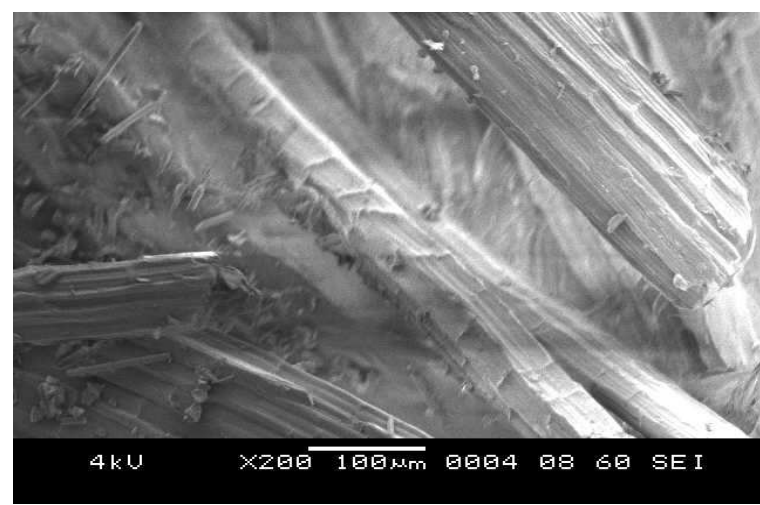

(a)

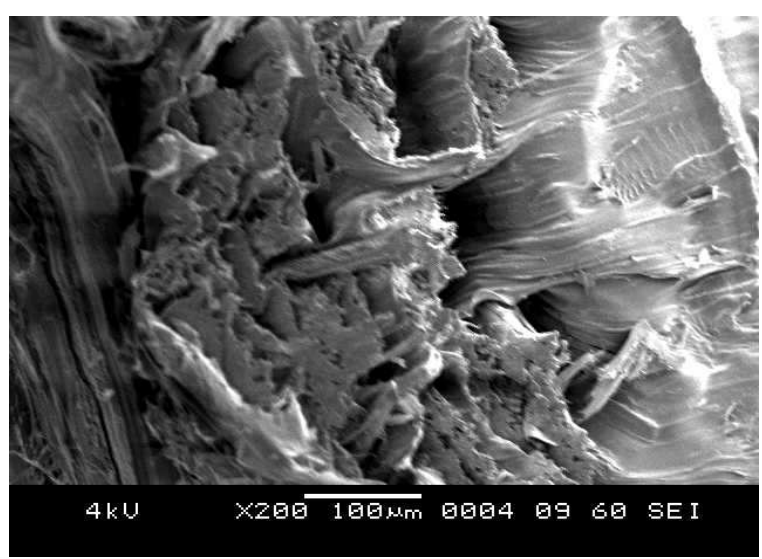

(c)

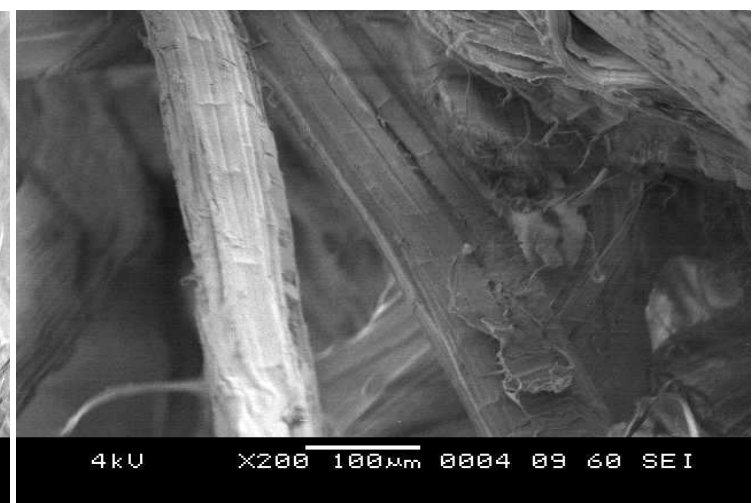

(b)

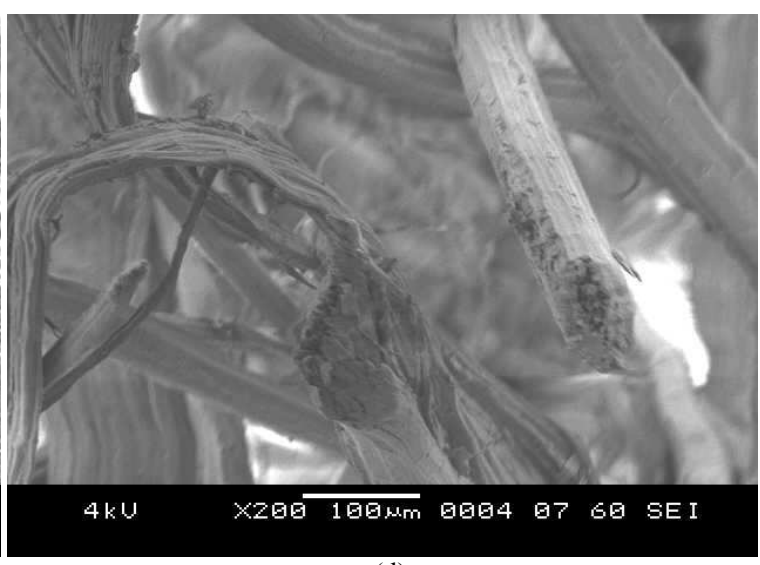

(d)

Fig. 4. SEM images of fracture surface of tensile specimens (a) WMBPs-5 (b) WMBPs-10 (c) WMBPs-15 (d) WMBPs-20 
Table 2. General information of used polymer material

\begin{tabular}{llll}
\hline Polymers & Source MFI & $\mathrm{g} / 10 \mathrm{~min}$ & Density g/cc \\
\hline BOPP & Reg pickers & 3.620 & 0.88 \\
LDPE & Reliance & 4.464 & 0.90 \\
LLDPE & Reliance & 8.446 & 0.92 \\
\hline
\end{tabular}

Table 3. Investigated data of LLDPE

\begin{tabular}{llll}
\hline Properties & Unit & Examine value & ASTM \\
\hline MFI $2.16 \mathrm{~kg} / 190^{0}$ & $\mathrm{C} \mathrm{g} / 10 \mathrm{~min}$ & 8.446 & $\mathrm{D} 1238$ \\
Density & $\mathrm{g} / \mathrm{cc}$ & 0.920 & $\mathrm{D} 792$ \\
Tensile Strength & $\mathrm{MPa}$ & 13.20 & $\mathrm{D} \mathrm{638}$ \\
\hline
\end{tabular}

Table 4. Investigated data of LDPE

\begin{tabular}{llcc}
\hline Properties & Unit & Examine value & ASTM \\
\hline MFI $2.16 \mathrm{~kg} / 190^{0}$ & $\mathrm{C} \mathrm{g} / 10 \mathrm{~min}$ & 4.46 & $\mathrm{D} 1238$ \\
Density & $\mathrm{g} / \mathrm{cc}$ & 0.90 & $\mathrm{D} 792$ \\
Tensile Strength & $\mathrm{MPa}$ & 11.00 & $\mathrm{D} 638$ \\
\hline
\end{tabular}

Table 5. Investigated data of BOPP

\begin{tabular}{llcc}
\hline Properties & Unit & Examine value & ASTM \\
\hline MFI & $\mathrm{g} / 10 \mathrm{~min}$ & 3.624 & $\mathrm{D} 1238$ \\
Density & $\mathrm{g} / \mathrm{cc}$ & 0.880 & $\mathrm{D} 792$ \\
Tensile Strength & $\mathrm{MPa}$ & 33.800 & $\mathrm{D} 638$ \\
\hline
\end{tabular}

Table 6. Investigated data of LLDPE: LDPE BLENDS

\begin{tabular}{llrl}
\hline Properties & Unit & Value & ASTM \\
\hline MFI & $\mathrm{g} / 10 \mathrm{~m}$ & 1.7936 & D1238 \\
Density & $\mathrm{g} / \mathrm{cc}$ & 0.9100 & D 792 \\
Tensile Strength & $\mathrm{MPa}$ & 10.8000 & D 638 \\
\hline
\end{tabular}

Table 7. Mechanical properties of different fiber content

\begin{tabular}{lll}
\hline Sample code & Tensile strength (MPa) & Impact strength $(\mathrm{MPa})$ \\
\hline WMBPs -0 & 13.8 & 35.2154 \\
WMBPs -5 & 17.5 & 37.2579 \\
WMBPs -10 & 18.7 & 42.9914 \\
WMBPs -15 & 25.7 & 48.6850 \\
WMBPs -20 & 22.1 & 53.2531 \\
\hline
\end{tabular}

\section{Impact Strength}

Figure 2 shows the effect of fiber content on the impact strength of LLDPE/LDPE and BOPP with sisal fiber. The impact strength is +35.3 , +37.25 , +43.1 , $+48.7,+53.26$ in $\mathrm{kJ} / \mathrm{m}^{2}$ for $0,5,10,15$ and $20 \%$ fiber content respectively. It can be noticed that impact strength increases with the increasing fiber content. However, increase of fiber fraction causes lack of energy absorbance.

\section{DSC Analysis}

DSC was used to evaluate the thermal property of LLDPE/LDPE and BOPP blends with sisal fibres. Energy absorb by the sample which shows the thermal transition in the sample. Figure 3 DSC graph shown the transition of plastic material in the sample as well as identification and composition of material. Peak
$112.80 \mathrm{C}$ shows first endothermic reaction of the sample which shows the M.P. of LDPE. The second peak at $124.60 \mathrm{C}$ shows the M.P. of LLDPE. The third peak at $162.40 \mathrm{C}$ shows the M.P. of PP.

\section{Conclusion}

The following conclusions drawn from this study.

LDPE: LLDPE and BOPP with sisal fibres have shown high tensile strength with the increase in fiber content up to $15 \%$ then decreases as high fiber content.

Flexural strength and modulus increase with the increase in fiber content.

Morphological observations show poor adhesion of fiber/matrix. This indicates that the fiber/matrix has poor interfacial bonding in low fiber content but increases at high fiber content between the matrix and fiber bonding. 
Impact strength increases with increase in fiber content. However, even with high fiber content of $20 \%$ the impact strength was high.

\section{Acknowledgement}

The author want to give thanks to Mr. Bikramjeet Singh and Mrs. Shubhajayraman technical officer CIPET Bhopal for providing the equipped material information and its testing.

\section{Funding Information}

Kiran Rohit is appreciative to the Director, MANIT, Bhopal for providing institute fellowship and infrastructure to hold out this analysis work.

\section{Author's Contributions}

Savita Dixit: All experiments were conducted beneath her supervising. All proof reading was done by her.

Kiran Rohit: She conducted the experiments and ensuant result analysis and discussion was conjointly done by her. She has written the manuscript for publication.

\section{Ethics (Conflicts of Interest)}

This article is pioneer and contains unpublished material. The corresponding author confirms that each one of the opposite authors have read and approved the manuscript and no moral problems concerned.

\section{References}

Alves, C., P.M.C. Ferrão, A.J. Silva, L.G. Reis and M. Freitas et al., 2010. Ecodesign of automotive components making use of natural jute fiber composites. J. Cleaner Product., 18: 313-327.

DOI: 10.1016/j.jclepro.2009.10.022

AL Oqla, F.M. and S.M. Sapuan, 2014. Natural fiber reinforced polymer composites in industrial applications: feasibility of date palm fibers for sustainable automotive industry. J. Cleaner Product., 66: 347-354 DOI: 10.1016/j.jclepro.2013.10.050

AL Oqla, F.M., O.Y. Alothman, M. Jawaid, S.M. Sapuan and M.H. Es-Saheb, 2014a. Processing and Properties of Date Palm Fibers and Its Composites. In: Biomass and Bioenergy: Processing and Properties, Hakeem, K.R., M. Jawaid and U. Rashid (Eds.), Springer, ISBN-10: 3319076418, pp: 1- 25.

AL Oqla, F.M., M.S. Sapuan, M.R. Ishak and N.A. Aziz, 2014b. Combined multi-criteria evaluation stage technique as an agro waste evaluation indicator for polymeric composites: Date palm fibers as a case study. Bioresources, 9: 4608-4621.
AL Oqla, F.M., S.M. Sapuan, M.R. Ishak and A.A. Nuraini, 2015a. Predicting the potential of agro waste fibers for sustainable automotive industry using a decision making model. Comput. Electr. Agric., 113: 116-127. DOI: 10.1016/j.compag.2015.01.011

AL-Oqla, F.M., S.M. Sapuan, M.R. Ishak and A.A Nuraini, 2015b. A novel evaluation tool for enhancing the selection of natural fibers for polymeric composites based on fiber moisture content criterion. Bioresources, 10: 299-312.

AL-Oqla, F.M., S.M. Sapuan, M.R. Ishak and A.A. Nuraini, 2015c. Decision making model for optimal reinforcement condition of natural fiber composites. Fibres Polymers, 16: 153-163. DOI: $10.1007 / \mathrm{s} 12221-015-0153-3$

Antonucci, V., F. Caputo, P. Ferraro, A. Langella and V. Lopresto et al., 2016. Low velocity impact response of carbon fiber laminates fabricated by pulsed infusion: A review of damage investigation and semi-empirical models validation. Progress Aerospace Sci., 81: 26-40.

DOI: $10.1016 /$ j.paerosci.2015.11.002

Caputo, F., A. De Luca, G. Lamanna, V. Lopresto and A. Riccio et al., 2015. Numerical investigation of onset and evolution of LVI damages in CarbonEpoxy plates. Comp. Part B Eng., 68: 385-391. DOI: 10.1016/j.compositesb.2014.09.009

Faruk, O., A.K. Bledzki, H.P. Fink and M. Sain, 2012. Biocomposites reinforced with natural fibers: 20002010. Progress Polymer Sci., 37: 1552-1596. DOI: 10.1016/j.progpolymsci.2012.04.003

Kalia, S., A. Dufresne, B.M. Cherian, B.S. Kaith and L. Avérous et al., 2011a. Cellulose-based bio- and nanocomposites: A review. Int. J. Polymer Sci., 2011: 1-35. DOI: $10.1155 / 2011 / 837875$

Kalia, S., B.S. Kaith and I. Kaur, 2011b. Cellulose Fibers: Bio- and Nano-Polymer Composites: Green Chemistry and Technology. Springer Science and Business Media, Berlin, ISBN-10: 3642173705, pp: 737.

Koronis, G., A. Silva and M. Fontul, 2013. Green composites: A review of adequate materials for automotive applications. Comp. Part B Eng., 44: 120-7 DOI: 10.1016/j.compositesb.2012.07.004

Megiatto, J.D., E.C. Ramires and E. Frollini, 2010. Phenolic matrices and sisal fibers modified with hydroxy terminated polybutadiene rubber: Impact strength, water absorption and morphological aspects of thermosets and composites. Indust. Crops Prod., 31: 178-84. DOI: 10.1016/j.indcrop.2009.10.001

Mohammed, L., M.N.M. Ansari, G. Pua, M. Jawaid and M.S. Islam, 2015. A review on natural fiber reinforced polymer composite and its applications. Int. J. Polymer Sci., 2015: 243947-243947.

DOI: $10.1155 / 2015 / 243947$ 
Riccio, A., F. Caputo, G. Di Felice, S. Saputo and C. Toscano et al., 2016. A joint numericalexperimental study on impact induced intra-laminar and inter-laminar damage in laminated composites. Applied Comp. Mater., 23: 219-237. DOI: $10.1007 / \mathrm{s} 10443-015-9457-0$

Sapuan, SM., F.I. Pua, Y.A. Shekeil, and F.M. AL-Oqla, 2013. Mechanical properties of soil buried kenaf fiber reinforced thermoplastic polyurethane composites. Mater. Design, 50: 467-470.

DOI: 10.1016/j.matdes.2013.03.013

Scarponi, C., and M. Messano, 2015 Comparative evaluation between E-glass and hemp fiber composite application in rotorcraft interior. Composite Part B Eng., 69: 542-9.

DOI: $10.1016 /$ j.compositesb.2014.09.010
Scarponi, C., and C. Andreotti, 2009. Industrial applications of natural fibers advanced composites: environment effects and comparative life cycle analysis. Int. J. Mater. Product. Technol., 36: 241-60.

Thakur, V.K., G. Ding, J. Ma and X. Lu, 2012. Hybrid materials and polymer electrolytes for electrochromic device applications. Adv. Mater., 24: 4071-4096. DOI: 10.1002/adma.201200213

Thakur, V.K. and M.K. Thakur, 2014. Processing and characterization of natural cellulose fibers/thermoset polymer composites. Carbohydrate Polymer, 109: 102-117. DOI: 10.1016/j.carbpol.2014.03.039

Thakur, V.K., M.K. Thakur and R.K. Gupta, 2014. Review: Raw natural fiber-based polymer composites. Int. J. Polymer Anal. Characterize., 19: 256-271. DOI: 10.1080/1023666X.2014.880016 